\title{
PRELIMINARY ANALYSIS OF THE STRUCTURAL AND INFLOW DATA FROM THE LIST TURBINE*†
}

\author{
Herbert J. Sutherland \\ Sandia National Laboratories \\ Albuquerque, NM 87185-0708
}

\begin{abstract}
The Long-term Inflow and Structural Test (LIST) program is collecting long-term, continuous inflow and structural response data to characterize the extreme loads on wind turbines. A heavily instrumented Micon $65 / 13 \mathrm{M}$ turbine with SERI $8 \mathrm{~m}$ blades is being used as the primary test turbine for this test series. This turbine is located in Bushland, TX, a test site that exposes the turbine to a wind regime that is representative of a Great Plains commercial site. The turbine and its inflow are being characterized with 60 measurements: 34 to characterize the inflow, 19 to characterize structural response, and 7 to characterize the timevarying state of the turbine. In a companion paper, Sutherland, Jones and Neal ${ }^{l}$ give a detailed description of the turbine, the site and the instrumentation. In this paper, a preliminary analysis of the structural and inflow data is presented. Particular attention is paid to the determination of the various structural loads on the turbine. Long-term fatigue spectra are also presented.
\end{abstract}

\section{INTRODUCTION}

The Long-term Inflow and Structural Test (LIST) program is collecting long-term, continuous inflow and structural response data to characterize the extreme loads that drive the design of wind turbines. As noted by Madsen, Pierce and Buhl, ${ }^{2}$ the extreme loads during normal operation in turbulent conditions may cause the maximum turbine response, even higher than the loads while parked in hurricane force winds. The fatigue damage to critical components, such as the blades, is dominated disproportionately by the highest operating loads even though their rate-of-occurrence is relatively small. Sutherland and Butterfield ${ }^{3}$ have discussed the views of a panel of experts convened to discuss these "extreme events." They conclude that the nature of the turbulence responsible for, and the dynamic structural response to, these high load events is not understood at this time. They further conclude that characterizing

\footnotetext{
Sandia is a multiprogram laboratory operated by Sandia Corporation, a Lockheed Martin company, for the U.S. Department of Energy under contract DE-AC04-94AL 85000.

This paper is declared a work of the U.S. Government and is not subject to copyright protection in the United States.
}

these extreme conditions will drive down the cost of wind turbine systems.

To characterize the spectrum of these lowoccurrence events requires a long-term, timesynchronized database that characterizes both the structural responses of the wind turbine and the inflow for at least a wind season. Numerous previous studies have examined the influence of various inflow parameters on structural response. However, most of these studies are typically too short to find the extremes, or they have limited inflow data. One notable exception is the study reported by Glinou and Fragoulis. ${ }^{4}$ In this detailed study, multiple turbines in complex mountain terrain are characterized with large arrays of inflow and structural measurements. Their work is serving as a guide for the LIST program.

In a companion paper, Sutherland, Jones and $\mathrm{Neal}^{1}$ present a detailed discussion of the LIST program, a test program designed to gather the required database for commercial size turbines at commercially interesting U.S. sites. The first phase of the program is the development, testing and demonstration of the instrumentation and data systems required to characterize the low-occurrence events. For this measurement campaign, a relatively small turbine is being used. The turbine, a Micon $65 / 13 \mathrm{M}$, is being tested at the USDA-ARS research center in Bushland, Texas, near Amarillo. This site is representative of a Great Plains commercial site. The turbine and its inflow are being monitored using a total of 60 instruments: 34 to characterize the inflow, 19 to characterize structural response, and 7 to characterize the time-varying state of the turbine.

This paper presents a preliminary analysis of the inflow and structural data, with emphasis on the latter. Detailed correlation of the extensive inflow and structural data is reserved for future analyses. In particular, this paper will concentrate on data that were taken over a single 24-hour period. During this period a total of 14410 -minute records was taken. These records are continuous, except for one 6-minute period when the data system was deactivated while the site operator addressed a twisted-power-cable-fault on the turbine. Other data are discussed as warranted. 


\section{DISCLAIMER}

This report was prepared as an account of work sponsored by an agency of the United States Government. Neither the United States Government nor any agency thereof, nor any of their employees, make any warranty, express or implied, or assumes any legal liability or responsibility for the accuracy, completeness, or usefulness of any information, apparatus, product, or process disclosed, or represents that its use would not infringe privately owned rights. Reference herein to any specific commercial product, process, or service by trade name, trademark, manufacturer, or otherwise does not necessarily constitute or imply its endorsement, recommendation, or favoring by the United States Government or any agency thereof. The views and opinions of authors expressed herein do not necessarily state or reflect those of the United States Government or any agency thereof. 


\section{DISCLAIMER}

Portions of this document may be illegible in electronic image products. Images are produced from the best available original document. 
Particular attention is paid to the determination of the various structural loads and fatigue spectra.

\section{THE LIST TURBINE}

The turbine used in this experimental investigation is a Micon $65 / 13 \mathrm{M}$ turbine. A complete description of the turbine, its site, and instruments used to monitor the turbine and its inflow are provided by Sutherland, Jones and Neal. ${ }^{\prime}$ A synopsis of this description is provided here for completeness.

\section{The Turbine}

The turbine used in this experimental investigation is a modified Micon 65/13 turbine (65/13M), see Fig. 1. This turbine is a fixed-pitch, 3-bladed up-wind turbine with a three-phase $480 \mathrm{v}$ asynchronous generator rated at $115 \mathrm{~kW}$. The generator operates at $1200 \mathrm{rpm}$ while the blades turn at a fixed $55 \mathrm{rpm}$ (the standard Micon $65 / 13$ turbine rotates at a fixed $45 \mathrm{rpm}$ ).

The turbine is fitted with Phoenix $8 \mathrm{~m}$ blades that are based on Solar Energy Research Institute (SERI) ${ }^{\ddagger}$ airfoils. These "SERT" blades are $7.9 \mathrm{~m}$ (312 in) long and are equipped with tip brakes.

This turbine is located with two similar turbines on the USDA Agriculture Research Service (ARS) site in Bushland, TX. This site is characteristic of a Great Plains site with essentially flat terrain. The primary wind direction at the site is from $215^{\circ}$ with-respect-to True North. The wind rosette for this site shows a secondary peak for winds from approximately due North.

\section{Instrumentation}

The turbine and its inflow are monitored using 60 instruments: 34 to characterize the inflow, 19 to characterize structural response, and 7 to characterize the time-varying state of the turbine.

Primary inflow measurements are obtained using 5 3-axis sonic anemometers located 1.8 diameters upwind (with-respect-to the prevailing winds) of the turbine. Four of these anemometers are placed about a circle, whose diameter is equal to that of the turbine. One each is placed at the top, bottom, left and right extremities of the circle. The final anemometer, located at the center of the circle, is aligned with the rotor hub. These detailed inflow measurements are augmented using cup anemometers and wind vanes placed strategically about the site.

The turbine's structural response is monitored primarily using strain gauges that are clustered on the (NREL)

I SERI is now the National Renewable Energy Laboratory
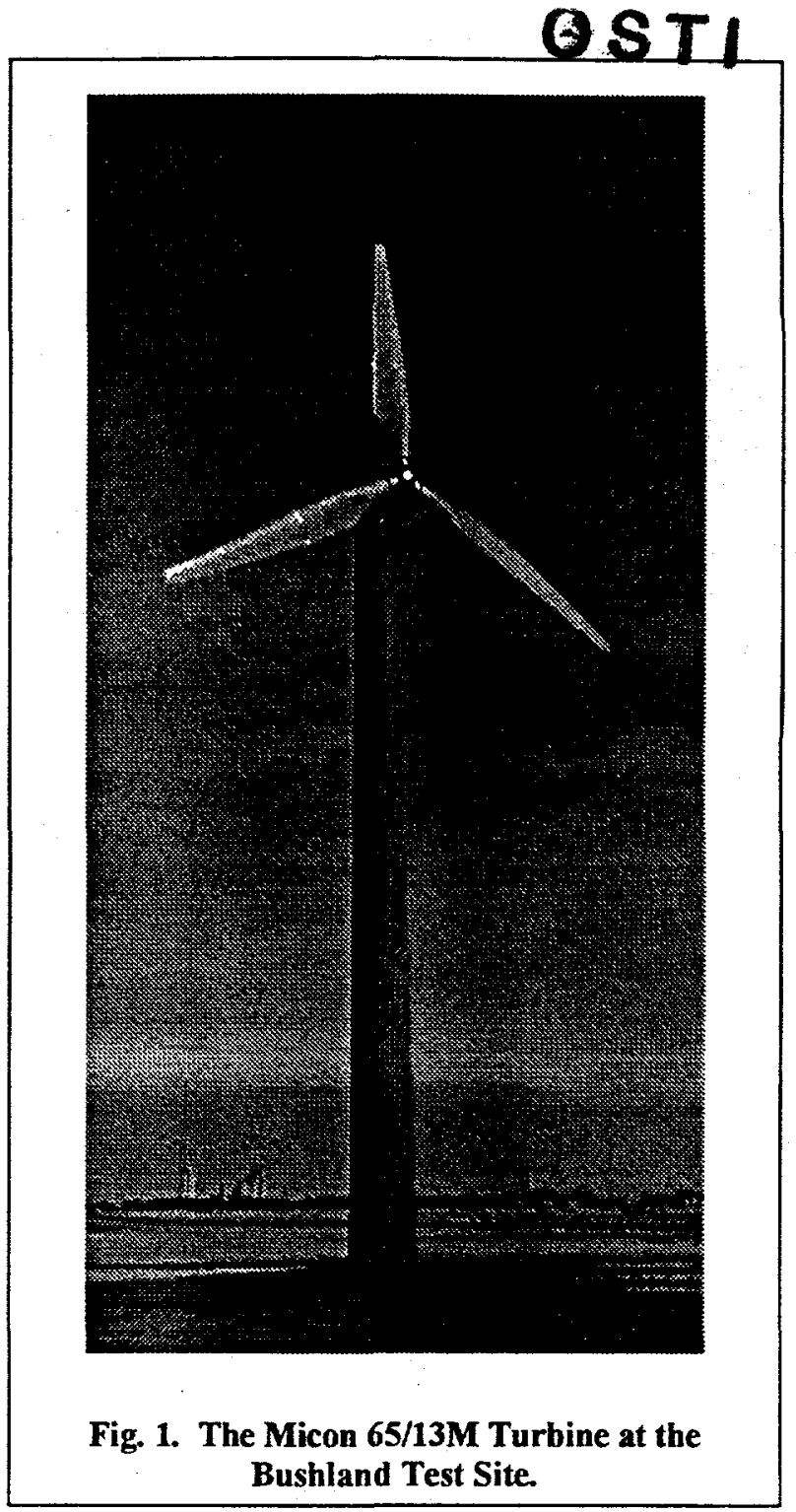

blade and the hub. Additional measurements include tower moments and nacelle accelerations.

Turbine state measurements include rotor position and speed, yaw position, power production and grid connection (on-off switch).

\section{Data Svstem}

The instruments cited above are monitored continuously using the Accurate, Time-Linked Data Acquisition System, ATLAS, described in detail by Berg, Rumsey and Zayas. ${ }^{5}$ The system monitors a total of 75 channels: 60 instrument channels and 15 time and status channels. The clocks on the system maintain a 1 micro-second accuracy using satellite links to the GPS system.

The data stream is monitored at a rate of $30 \mathrm{~Hz}$. This yields a Nyquist Frequency of $15 \mathrm{~Hz}$, which is 
sufficient for capturing the behavior of the inflow and the structural response of the turbine. ATLAS uses a second-order anti-aliasing active filter followed by a programmable fifth-order Butterworth filter. The cutoff frequency for the latter filter was set to $15 \mathrm{~Hz}$.

The data system automatically segments the data into 10-minute blocks, converts the data into engineering units, and archives them for future processing.

\section{PREVIOUS TESTING OF THE MICON 65/13 TURBINE}

Tangler, et al., ${ }^{6,7}$ tested a similar blade/turbine combination in San Gorgonio Pass, California. The data from that blade/turbine system are not directly comparable to the data cited here because the turbines are very different. In particular, the turbine tested here has a larger generator ( $115 \mathrm{~kW}$ rather than $65 \mathrm{~kW}$ ) and a faster rotation rate $(55 \mathrm{mpm}$ rather than $45 \mathrm{rpm})$.

Although built by the same manufacturer with the same external shape, the blades tested here are also different. The difference, essentially the difference between a prototype blade and a production blade, is manifested as an increase in blade weight. Namely, the LIST blades are approximately 15 percent $[0.45 \mathrm{kN}$ $(100 \mathrm{lb})]$ heavier ${ }^{8}$ than the blades tested by Tangler, et al. ${ }^{6,7}$ The effect of the additional weight on modal response is not readily comparable in the two data sets.

Unfortunately, these differences preclude direct comparisons of the data gathered in these two measurement campaigns. However, when warranted, similarities and differences in the data sets are discussed.

\section{A TYPICAL DATA SET}

Most of the data cited in Sutherland, Jones and $\mathrm{Neal}^{1}$ are taken from the data sets that were taken during a single 24-hour period, approximately midnight to midnight on May 17, 2000. During this period, a total of 144 10-minute data sets was taken. These records are continuous, except for one 6-minute period when the data system was deactivated while the site operator addressed a twisted-power-cable-fault on the LIST turbine. These data were chosen for discussion here because the wind speed was above $15 \mathrm{~m} / \mathrm{s}$ for a significant portion of the day. A continuous 24-hour period was chosen to illustrate the capabilities of the ATLAS.

The data analysis presented here has been developed using the SDAS, GPP and CRUNCH software packages. These packages are described in detail in Refs. 5, 9 and 10, respectively.

\section{Wind Spectrum}

During the 24-hour period, the average wind speed at hub height was $12.8 \mathrm{~m} / \mathrm{s}$ and the average 10 -minute turbulence intensity was 12.3 percent. The 10 -minute averages for wind speed and turbulence intensity are summarized in Figs. 2 and 3, respectively.

As shown in Fig. 2, this particular day has a significant period with the wind speed above $15 \mathrm{~m} / \mathrm{s}$. The distribution of wind speeds is shown in Fig. 4.

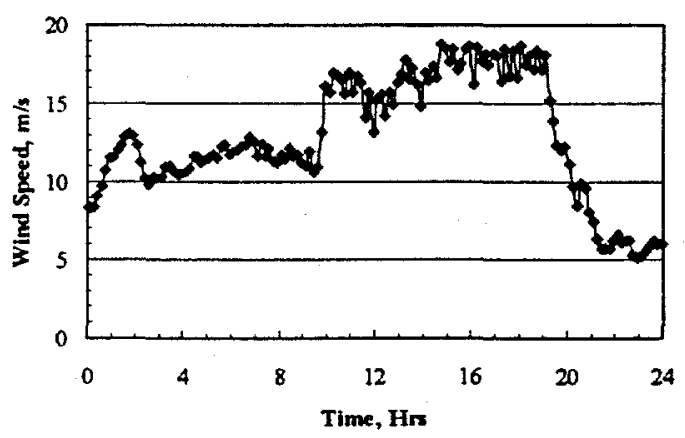

Fig. 2. Wind Speed Distribution Based on 10Minute Averages for the 24-Hour Period.

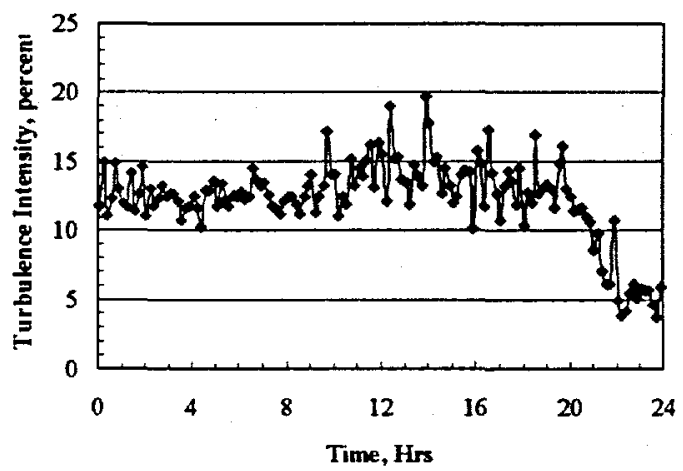

Fig. 3. Turbulence Intensity Based on 10Minute Data Sets for the 24-Hour Period.

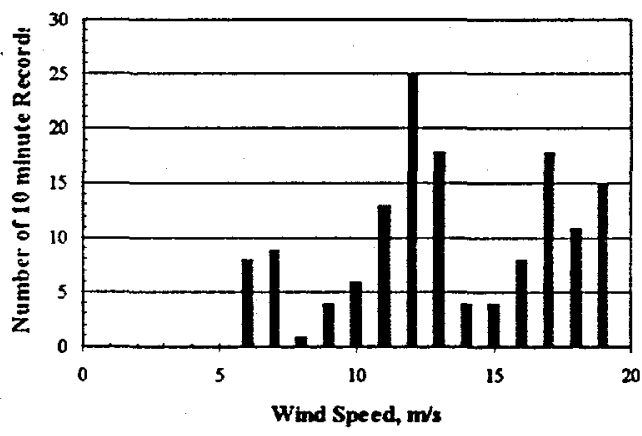

Fig. 4. Distribution of Wind Speeds for the 24Hour Period. 
These data may also be binned by wind speed class. Wind speed bin class 3 encompasses speeds to 9 $\mathrm{m} / \mathrm{s}$. Bin classes 4, 5, 6 and 7 encompass speed ranges of 9-11, 11-13, 13-15 and $15-17 \mathrm{~m} / \mathrm{s}$, respectively. Bin class 8 encompasses all wind speeds above $17 \mathrm{~m} / \mathrm{s}$. For this 24-hour period, there are 22 10-minute data sets in class 3,19 in class 4,43 in class 5,8 in class 6 , 26 in class 7 and 26 in class 8 . The average turbulence intensities for wind speed classes 3 through 8 are 7.17, $12.16,12.64,16.01,13.93$, and 13.28 percent, respectively.

In addition to measuring the two components of horizontal wind speed, the 3 -axis sonic anemometers also measured the vertical wind speed. Typical of these data is the hub-height vertical inflow velocity reported by Sutherland, Jones and Neal, ${ }^{1}$ repeated here in Fig. 5. When combined with horizontal wind-speed measurements, such parameters as the instantaneous Reynolds stress components ${ }^{11,12}$ can be determined, see Fig. 6. The component plotted here is the horizontal/vertical Reynolds stress, u'w'. These instantaneous values yield an average local friction velocity $\mathrm{u}^{*}$ of $0.63 \mathrm{~m} / \mathrm{s}$ for this 10 -minute record.

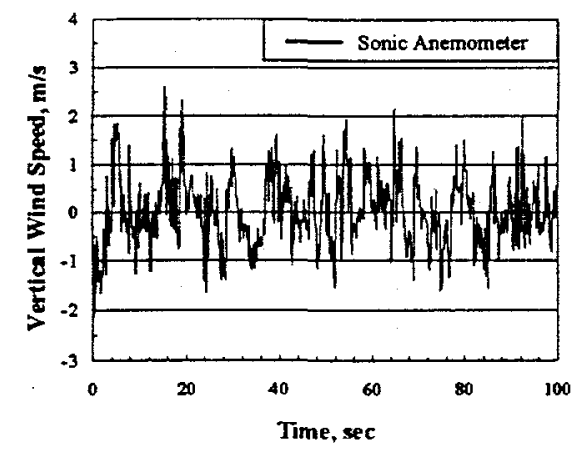

Fig. 5. Typical Vertical Wind Speed.

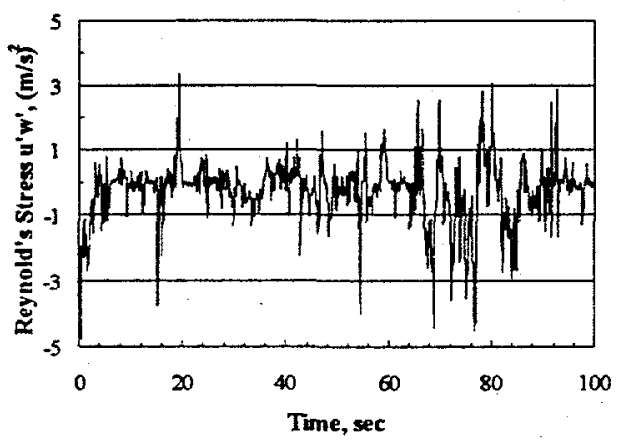

Fig. 6. Instantaneous Reynolds Stress for the Horizontal and Vertical Velocity Components.
During this period, the mean horizontal wind speed was $12.2 \mathrm{~m} / \mathrm{s}$ and the turbulence intensity was 11.9 percent.

In addition to hub-height data presented here, the other four 3-axis sonic anemometers are monitoring the inflow about the rotor.' The wealth of information provided by these five sonic anemometers provide a detailed description of the inflow and, ultimately, will permit the development of relationships between inflow parameters and structural response. As noted above, a detailed correlation of the inflow and structural response data gathered in LIST program is reserved for future analyses. Also as noted above, many, including Glinou and Fragoulis, ${ }^{4}$ have studied this class of relationships. The LIST program is designed to build upon their studies.

\section{STRUCTURAL RESPONSE}

The structural response of the LIST turbine blades is monitored using 6 bending-gauge circuits on the hub and 6 at the 40 percent span of the blades. Both flap and edge moments are measured at each of these stations. A typical set of time-series data for edge and flap bending is shown in Sutherland, Jones and Neal ${ }^{3}$ These data are repeated here, see Fig. 7 and 8 for completeness. The strain gauge data shown in these two figures corresponds to the same 10-minute data set cited above in Figs. 5 and 6.

\section{Power Spectral Density}

The power spectral densities (PSD) for root edge and flap bending are shown in Figs. 9a and 9b. These figures illustrate that the SERI blades are very active at all multiples of the rotational speed. The primary bending moment harmonic in both the edge and flap directions occurs at the system rotation rate, IP, of 0.92 $\mathrm{Hz}(55 \mathrm{rpm})$. Most of the other multiplies of the rotation rate are represented by spikes in the PSD curve.

This response is significantly larger than the response measured by Tangler et. al. ${ }^{7}$ This increase is to be expected because the SERI blades were optimized for a rotation speed of $45 \mathrm{rpm}$.

As shown in Fig. 9a, the edge-bending response of the blades has two major peaks at $1 \mathrm{P}(0.92 \mathrm{~Hz})$ and $7 \mathrm{P}$ $(6.42 \mathrm{~Hz})$. In the earlier test series, major peaks were observed at $1 \mathrm{P}(0.75 \mathrm{~Hz})$ and $9 \mathrm{P}(6.75 \mathrm{~Hz})$. As the first edge mode of the blade/hub combination occurs at approximately $7 \mathrm{~Hz}^{7}$, thus the large resonance observed in Fig. $7 \mathrm{~b}$ at $7 \mathrm{P}$ and the corresponding resonance observed by Tangler et. al. ${ }^{7}$ at $9 \mathrm{P}$ is expected.

The flap bending response, see Fig. 9b, also illustrates the very active nature of this blade/turbine combination, with major peaks occurring at the first four multiplies of IP. The data presented by Tangler 


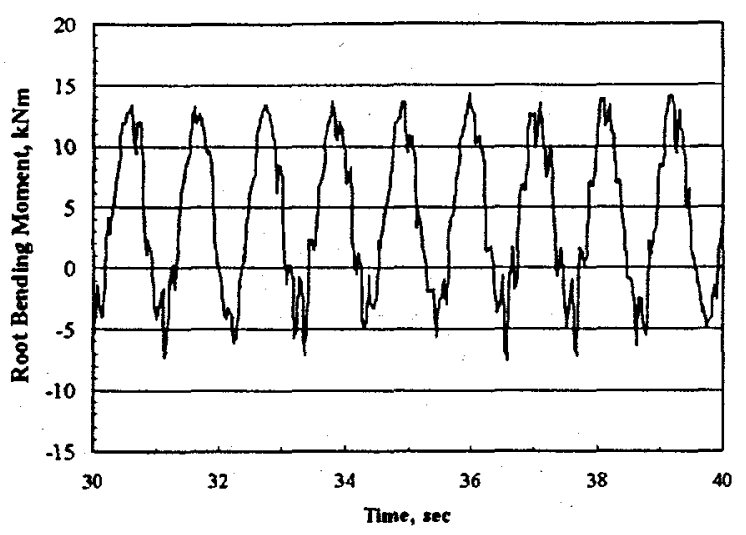

Fig. 7a. Ten Seconds of Time-Series Data.

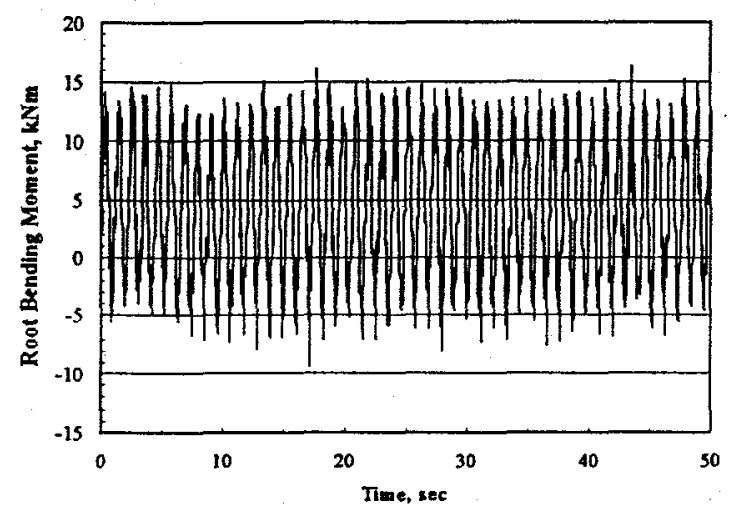

Fig. 7b. Fifty Seconds of Time-Series Data.

Fig. 7. Edge-Bending Moment in the Root of Blade 1.

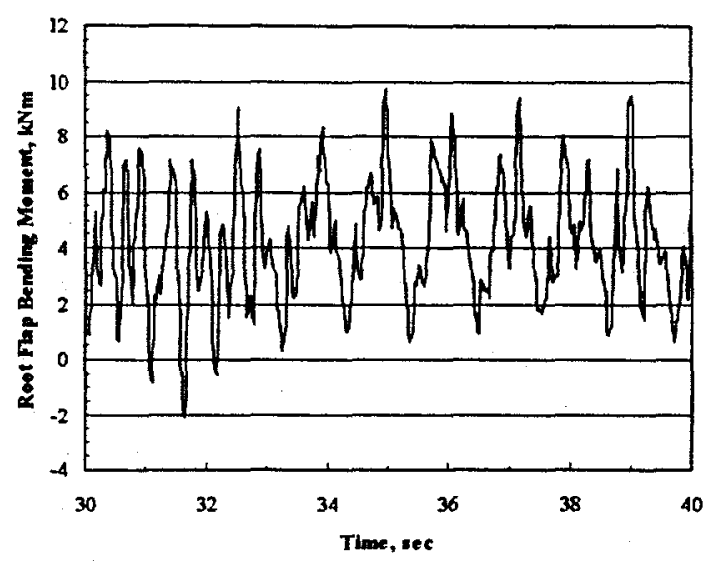

Fig. 8a. Ten Seconds of Time-Series Data.

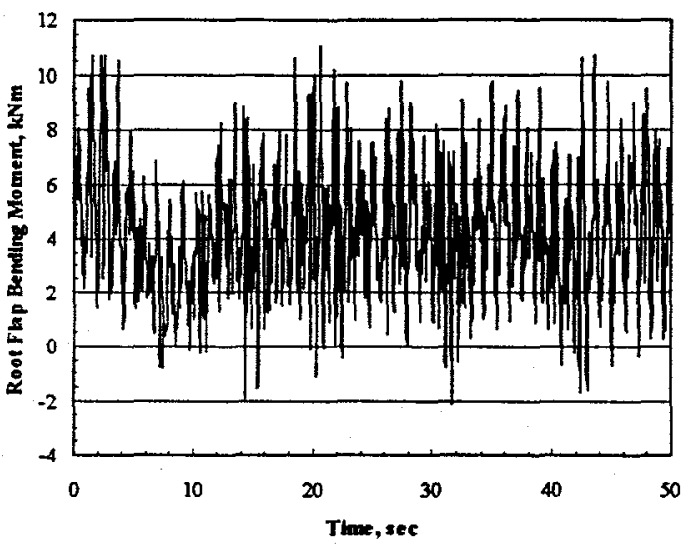

Fig. 8b. Fifty Seconds of Time-Series Data.

Fig. 8. Flap-Bending Moment in the Root of Blade 2.

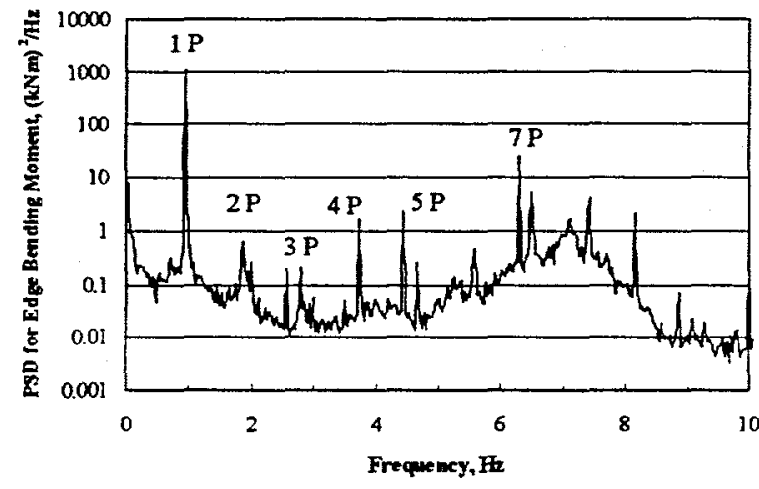

Fig. 9a. Root Edge-Bending Moment.

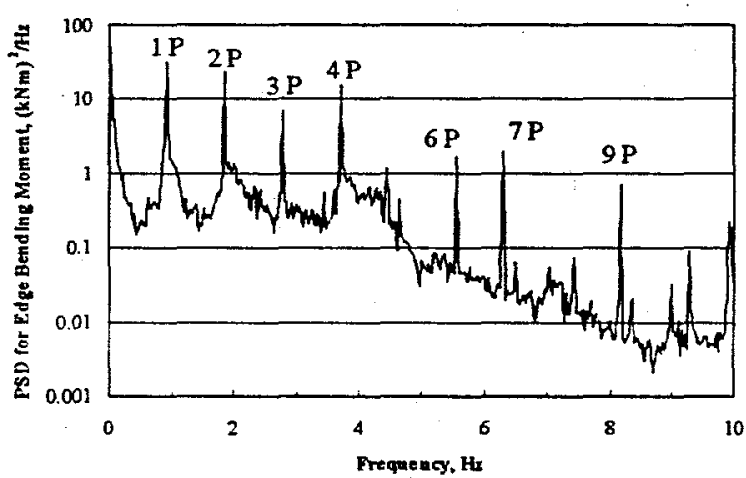

Fig 9b. Root Flap-Bending Moment

Fig. 9. Power Spectral Density. 
et.al. ${ }^{7}$ yield similar results, except for the peak at $3 \mathrm{P}$, which is not present in the locked-yaw data. With active yaw, the $3 \mathrm{P}$ harmonic dominates and the $4 \mathrm{P}$ largely disappears.

\section{Azimuth-Averaged Edge-Bending Moment}

Typical edge-bending moments, as a function of the azimuth position, are shown in Fig. 10. These illustrations correspond to the time series data shown in Figs. 7 and 8.

The blade weight was determined by O'Goram and Simmermacher ${ }^{8}$ to vary between approximately 3.31 and $3.34 \mathrm{kN}$ (745 and $750 \mathrm{lbs})$. Their centers of gravity were located at approximately $2.36 \mathrm{~m}$ (93 in) from the blade flange. Thus, the edge-bending moment at the root of the blade due to gravity should be approximately $8.8 \mathrm{kN}-\mathrm{m}$ when the blade is horizontal. When the mean is removed from the data shown in Fig. $10 \mathrm{a}$, the variation in bending moments ranges between $8.5 \mathrm{kNm}$ at an azimuth position of $90^{\circ}$ and $8.4 \mathrm{kNm}$ at $270^{\circ}$.

A similar plot for the edge-bending stress in the blade at the 40 percent span location is shown in Fig. $10 \mathrm{~b}$. In this figure, data for blades 2 and 3 are shown. These plots are essentially overlays of one another when Blade 2's plot is shifted $120^{\circ}$.

\section{FATIGUE SPECTRA}

One of the long-term objectives of the LIST program is to obtain long-term fatigue spectra for the turbine blade loads. As illustrated by the 24-hour period under discussion here, the ability to obtain continuous data enables a large quantity of fatigue data to be obtained in a relatively short period, and it provides researchers with the data they require to validate their inflow and structural models.

\section{Class 7 Spectra}

The fatigue spectra for a given wind speed bin (or wind speed class) are typically derived from a relatively short period of data, i.e., of the order of an hour, although that practice is changing. ${ }^{2}$ Figures 11 and 12 illustrate the short-term fatigue spectra for 1 hour of class 7 wind speed data that has been extracted from the 24-hour data set cited above. In contrast to the relative short data set used in these two figures, Fig. 13 illustrates the fatigue spectra when the class 7 data set is extended to 4.3 hours. Fig. 14 compares the 4.3 -hour data set to the 1-hour set.

In these figures, and all other fatigue spectra figures, the cycle counts have been normalized to cycles per second.

\section{One-Hour Spectra}

To illustrate the fatigue spectrum derived from a relatively short data set, the first continuous hour of class 7 winds was extracted from the 24-hour data set. The resulting fatigue spectra are presented in various forms in Figs. 11 and 12. During this 1-hour period, the mean wind speed was $16.3 \mathrm{~m} / \mathrm{s}$ and the turbulence intensity was 13.5 percent.

Figure 1la illustrates the fatigue spectrum for edge-bending in the root of blade 1 that is binned by the mean and the range of the fatigue cycle. Figure $11 \mathrm{~b}$ illustrates the fatigue spectrum for flap-bending in the root of blade 2 .

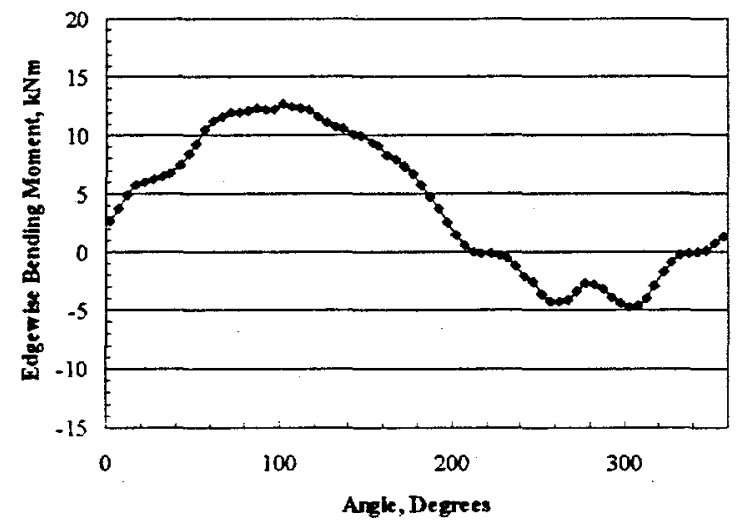

Fig 10a. Root Edge-Bending Moment in Blade 1.

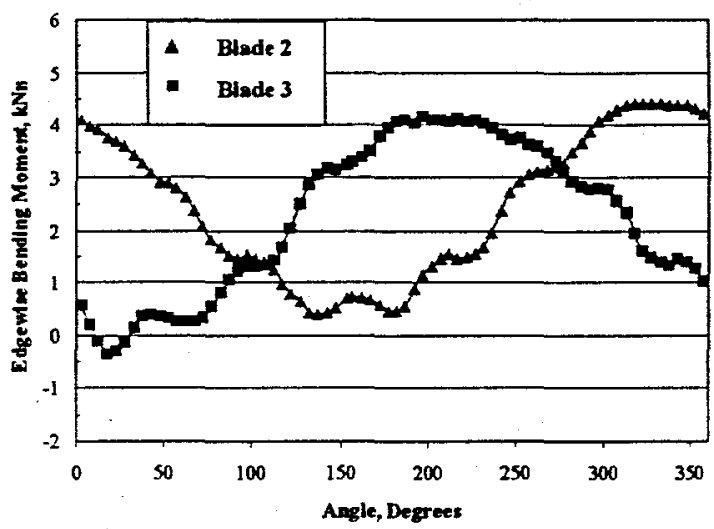

Fig. 10b. Blade Edge-Bending Moment in Blades 2 and 3, 40 percent Span.

Fig. 10. Azimuth Averaged Edge-Bending Moment. 


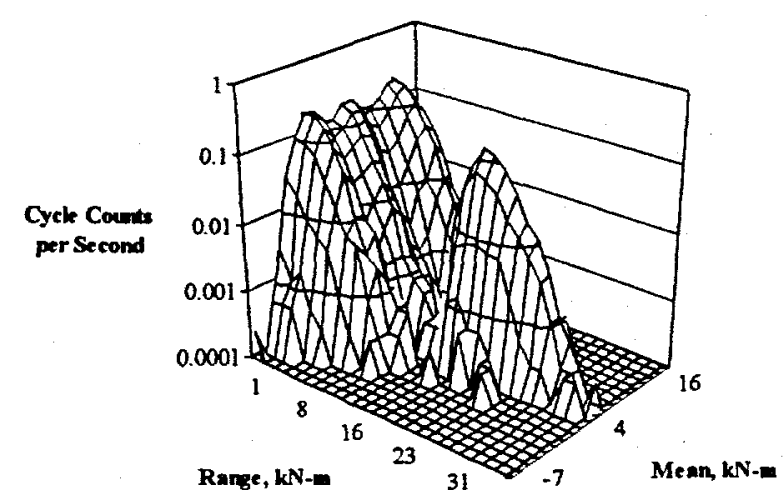

Fig. 11a. Root Edge-Bending in Blade 1.

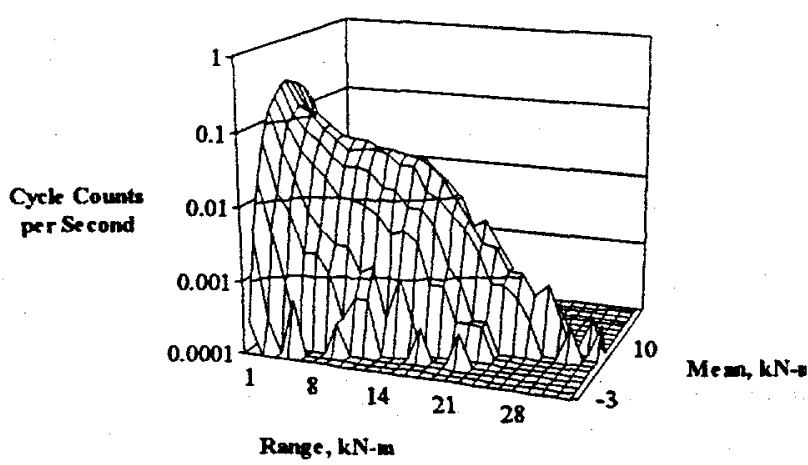

Fig. 11b. Root Flap-Bending in Blade 2.

Fig. 11. Fatigue Load Snectrum for 1-Hour in Class 7 Winds.

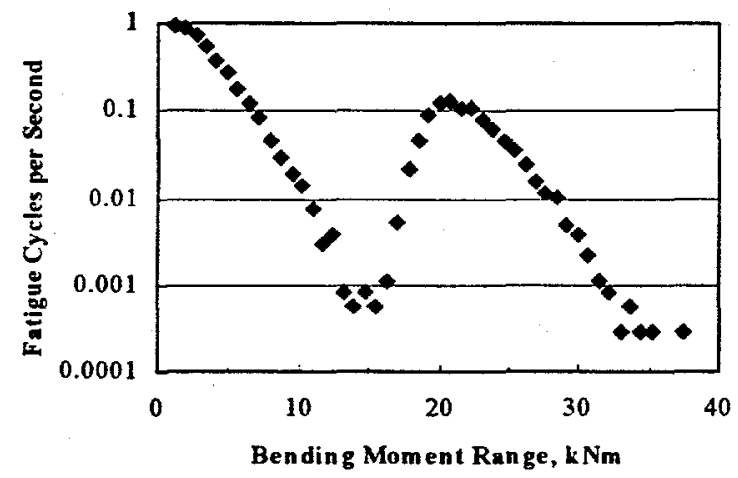

Fig. 12a. Edge Bending in the Root of Blade 1.

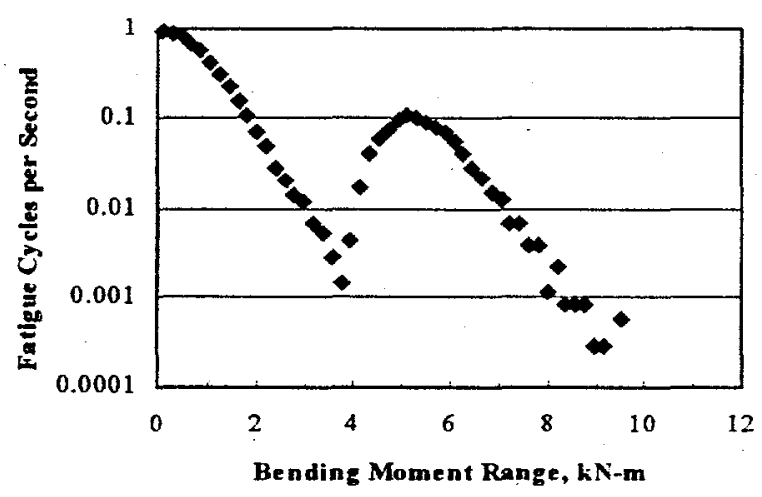

Fig. 12c. Edge Bending in the Blade 2 at 40 Percent Span.

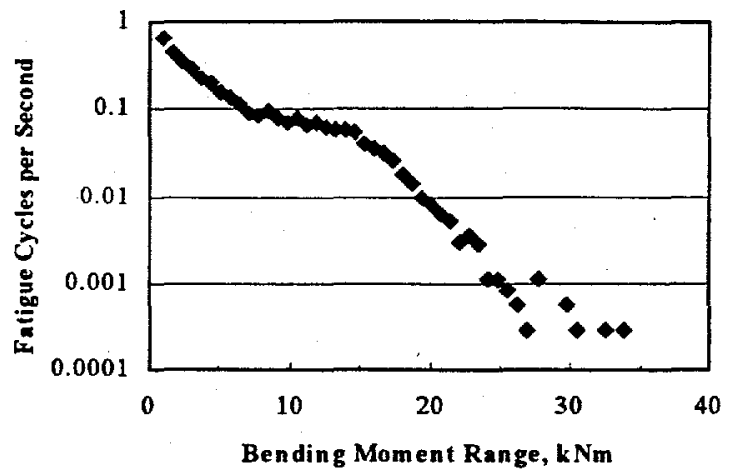

Fig. 12b. Flap Bending in the Root of Blade 2.

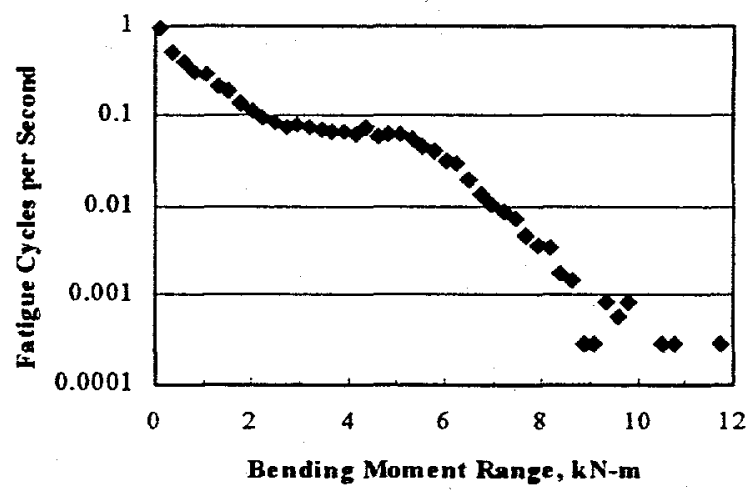

Fig. 12d. Flap Bending in the Blade 2 at 40 Percent Span.

Fig. 12. Fatigue Load Spectrum for Class 7 Wind Speeds, One-Hour of Data. 


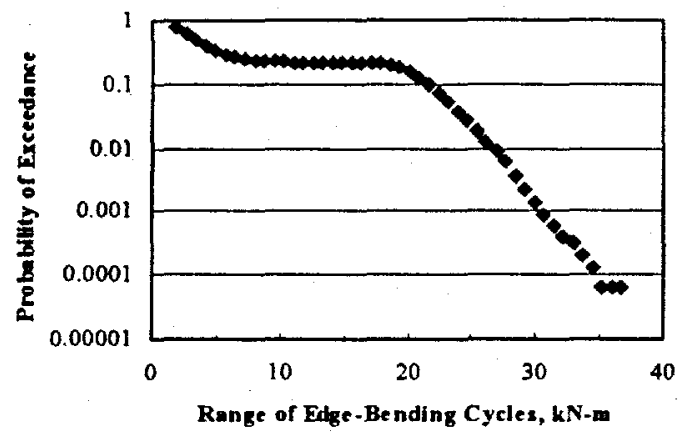

Fig. 13a. Edge-Bending in the Root of Blade 1.

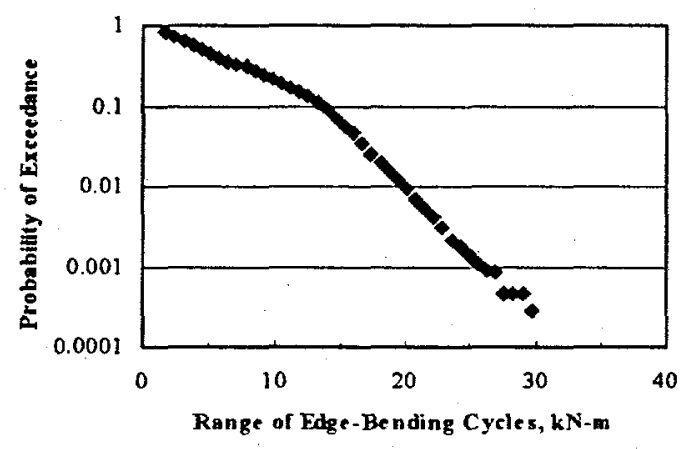

Fig. 13b. Flap-Bending in the Root of Blade 2.

Fig. 13. Exceedance Plots of the Fatigue Load Spectrum for Class 7 Wind Speeds, 1 Hour of Data.

Additional plots of these data, binned only by their range, are shown in Fig. 12. Figure 12a and $12 \mathrm{~b}$ are equivalent to Figs. 11a and $11 \mathrm{~b}$, respectively. Figures $12 \mathrm{c}$ and $12 \mathrm{~d}$ illustrate the edge and flap bending fatigue load spectra, respectively, at the 40 percent span station of the blade.

In the spectra presented in Fig. 12, many of the highest bins contain only 1 cycle count. This so-called "floor" occurs at approximately 0.0003 cycle counts per second for the 1-hour data set, i.e., one cycle per hour. This floor is easily observed in the data presented in Fig. 12a and $12 \mathrm{~b}$ in bins above approximately $35 \mathrm{kNm}$ and $30 \mathrm{kNm}$, respectively. This floor corresponds to a probability of exceedence of 0.00007 for cycle counts of the root edge-bending moment, see the bins above approximately $35 \mathrm{kNm}$ in Fig. 13a. For the flapbending moment, the probability at the floor is 0.0005 , see the bins above approximately $30 \mathrm{kNm}$ in Fig. 13b. The importance of the floor is that it defines the region of the spectra where the data are not statistically significant.

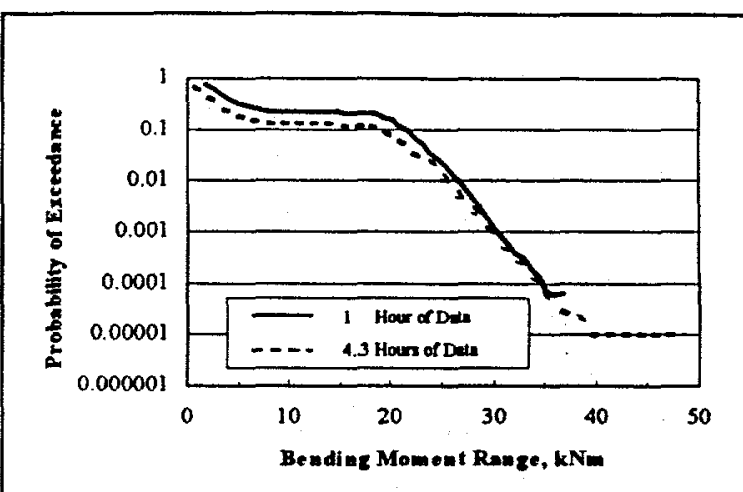

Fig. 14a. Edge-Bending in the Root of Blade 1.

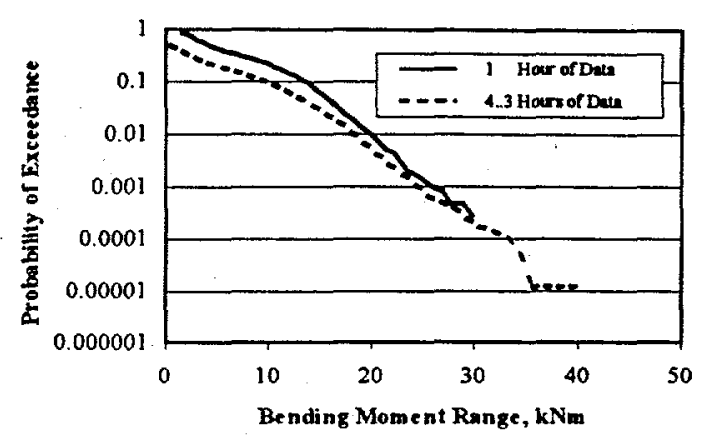

Fig. 14b. Flap-Bending in the Root of Blade 2.

Fig. 14. Exceedance Plots of the Fatigue Load Spectrum for Class 7 Wind Speeds.

These spectra are typical of the fatigue spectra that one would expect for this class of turbines. Namely, the edge-bending spectra display a bi-modal distribution, see Figs. 12a and 12c, that is directly attributed to the large 1P component of the bending moment observed in Fig. 7.

As illustrated in Figs. 12b and 12d, the fatigue spectrum for flap-bending moment has a very different character, with a single-mode distribution. There does appear to be a "step" near the $10-\mathrm{kNm}$ bending moment range that may be indicative of the strong $1 P$ harmonic observed in Fig. 8b.

To examine this possibility, exceedance plots of the data presented in Figs. $12 \mathrm{a}$ and $12 \mathrm{~b}$ were constructed, see Figs. 13 and 14. In this class of plots, a single-mode distribution will plot as a monotonically decreasing function, and a bi-modal distribution will plot as two monotonically decreasing functions separated by a region with a constant amplitude, commonly called a "flat."

As shown in Fig. 13a, the bi-modal nature of the edge bending spectra is readily apparent, with a long 
flat occurring between approximately 10 and $20 \mathrm{kNm}$. At the largest bending moments, above approximately $35 \mathrm{kNm}$, another flat is observed. This flat is formed by the floor for the 1-hour data set. Thus, the data in these bins are not statistically significant, and the flat is not indicative of another mode in the fatigue spectrum.

A similar plot for the flap bending is shown in Fig. 13b. There appears to be a change in slope near approximately $15 \mathrm{kNm}$, but there is no long flat that would indicate a significant second mode in the flapbending load spectrum. Again, the flat at the highest moments is indicative of the floor in the data and is not statistically significant.

\section{Multi-Hour Spectra}

To obtain statistically valid load spectra in the high bending moment region of the spectra require more than a single hour of data. For the 24-hour period under analysis, a total of 26 ten-minute data records, 4.3 hours, are available with Class 7 winds. During this period, the mean wind speed was $16.3 \mathrm{~m} / \mathrm{s}$ and the turbulence intensity was 14.4 percent.

The analysis of these 26 records is summarized in exceedance plots shown in Fig.14. As shown in this figure, the addition of 3.3 hours to the data set has

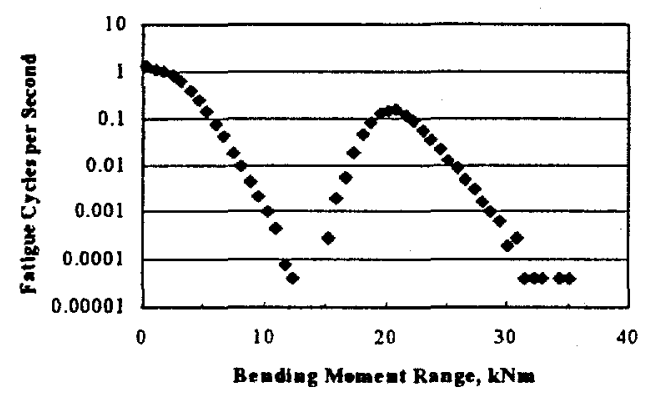

Fig. 15a. Edge-Bending in the Root of Blade 1.

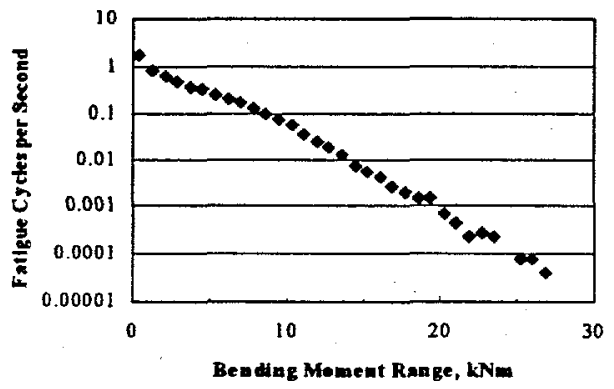

Fig. 15b. Flap-Bending in the Root of Blade 2.

Fig. 15. Cycle Counts of the Fatigue Load Spectrum for Class 5 Wind Speeds, 7.2 Hours of Data. extended the statistically significant range by approximately a half-order-of-magnitude. The new floor for these data is approximately 0.00006 cycles per second (one cycle per 4.3 hours). In both the edge and the flap bending cases, the 4.3-hour exceedance curve lies virtually on top of the 1-hour curve until the floor in the 1-hour data set is reached.

The significant difference between the two data sets is that the expansion of the data set to 4.3 hours extends the exceedance curve to a new floor. In particular, the additional data indicates that the primary slope of the exceedance curve in the high bending moment region of the spectrum continues unabated past the floor of the 1-hour data set.

\section{Class 5 Spectra}

A significantly larger set of 10-minute data records is available in the 24-hour data set for class 5 wind speeds. A total of 43 records, 7.16 hours, is available, which yields a floor of approximately 0.00004 cycles, see Fig. 15. During this period, the mean wind speed was $11.9 \mathrm{~m} / \mathrm{s}$ and the turbulence intensity was 13.4 percent. The cycle counts and the exceedance curves for these data are shown in Figs. 15 and 16, respectively.

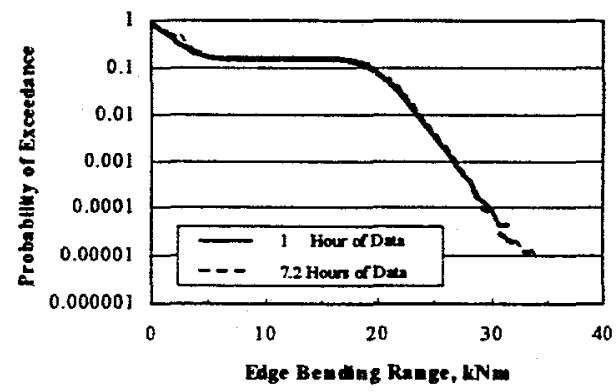

Fig. 16a. Edge-Bending in the Root of Blade 1.

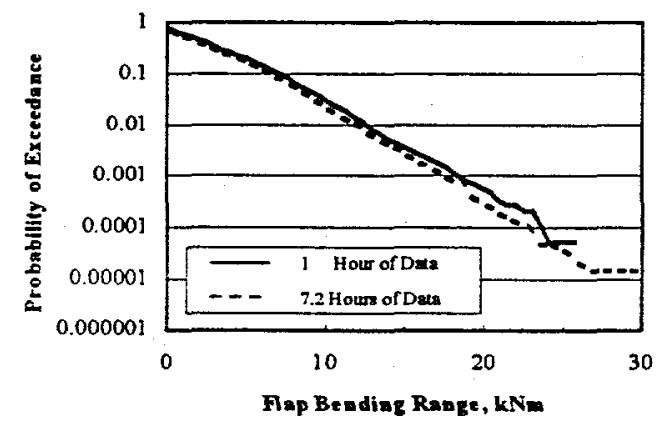

Fig. 16b. Flap-Bending in the Root of Blade 2.

Fig. 16. Exceedance Plots of the Fatigue Load Spectrum for Class 5 Wind Speeds. 
Again, these data illustrate that the slope of the exceedance curve in the high bending moment region of the spectrum continues unabated past the floor of a 1hour data set.

\section{4-Hour Spectra}

When all 144 10-minute records for this 24-hour period are cycle counted together, the result is shown in Fig. 17. This data set yields a floor of approximately 0.00001 cycles. During this period, the mean wind speed was $12.8 \mathrm{~m} / \mathrm{s}$. As shown in this figure, the spectra do not hold any surprises. Namely, the edgebending spectrum displays a bi-modal distribution and the flap-bending spectrum displays a single-mode distribution.

\section{CONCLUDING REMARKS}

The data discussed in this paper are unprecedented in the United States. Namely, the LIST program is collecting long-term continuous inflow and structural response data. This paper has concentrated on the

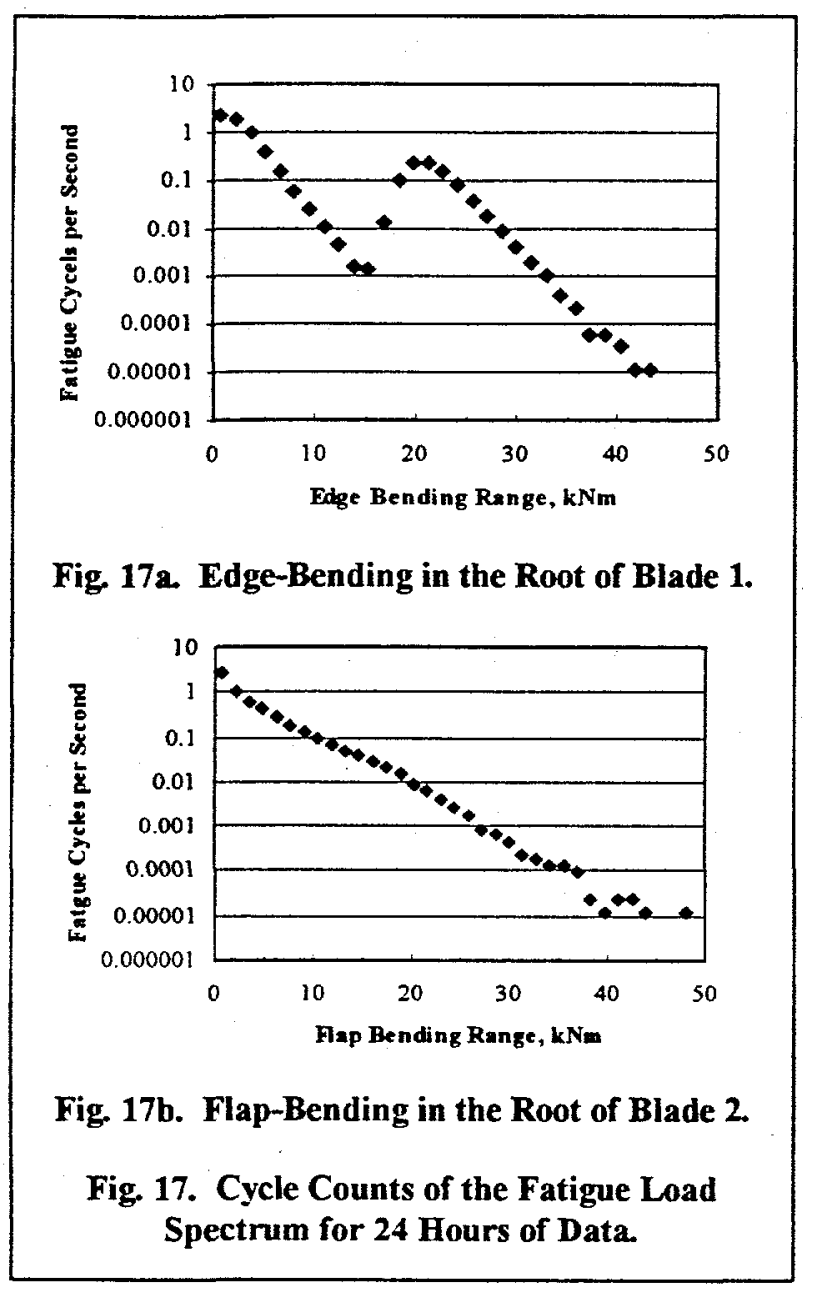

structural aspects of the data, with the presentation and preliminary analysis of a continuous 24-hour data set. Particular attention was paid to an examination of fatigue spectra for this turbine. Typical spectra by wind speed class and for continuously varying wind conditions are presented.

Structural fatigue data of the class presented here, and exemplified by the typical data presented in Fig. 17 , will permit the determination of highest operating loads on a turbine even though they occur rarely.

Significantly, these structural data are less than half of the entire data set available for analysis. Namely, in addition to structural data, the data set contains a wealth of inflow data. The preliminary analysis of these data presented here is only an indication of the type and depth of inflow information available from this measurement system. A detailed correlation of the inflow and structural response data gathered in LIST program is reserved for future analyses.

Thus, the LIST program is well on its way in the collection of a long-term database that characterizes the inflow and structural behavior of a wind turbine. As noted in Sutherland, Jones and Neal, ${ }^{1}$ the testing of the Micon turbine in Bushland is just the first measurement campaign. Future plans call for similar campaigns to conducted on large, commercial grade turbines at a variety of U.S. wind sites.

\section{ACKNOWLEDGEMENTS}

The data analyzed in this report are the result of a team effort. The personnel (including the author) and their primary duties in this project are: Henry Dodd: Program Manager, SNL; Nolan Clark: Program Director, USDA-ARS; Herb Sutherland: Project Leader; Byron Neal: Site Engineer, USDA-ARS; Perry Jones: Site Engineer, SNL; Dale Berg and Jose Zayas: Data Acquisition System; Mark Rumsey: Data Analysis System; Tom Ashwill: Construction and Foundation Design; Clint Sanders: Student Assistant.

\section{REFERENCES}

1. Sutherland, H.J., P.L. Jones, and B. Neal, "The Long-Term Inflow and Structural Test Program," 2001 ASME Wind Energy Symposium, 2001, in publication.

2. Madsen, P.H., K. Pierce and M. Buhl, "Predicting Ultimate Loads for Wind Turbine Design," 1999 ASME Wind Energy Symposium, 1999, p. 355.

3. Sutherland, H.J., and C.P. Butterfield, “A Summary of the Workshop on Fatigue Life Methodologies for Wind Turbines," Proceedings of WindPower '94, AWEA, Washington, DC, May, 1994. 
4. Mounturb Final Report, G. Glinou and A. Fragoulis, eds., 3 vols., JOU2-CT93-0378, November, 1996.

5. Berg, D.E., M.A. Rumsey and J.R. Zayas, "Hardware and Software Developments for the Accurate Time-Linked Data Acquisition System," 2000 ASME Wind Energy Symposium, 2000, p. 306.

6. Tangler, J., B. Smith, D. Jager, and T. Olsen, Atmospheric Performance of the SERI Thin-Airfoil Family, SERI/TP-257-3939, Solar Energy Research Institute, Golden, CO, 1990.

7. Tangler, J., B. Smith, D. Jager, E. McKenna, and J. Allread, "Atmospheric Performance Testing of the Special-Purpose SERI Thin Airfoil Family: Preliminary Results," Proceedings of Windpower '89, SERI/TP257-3628, Solar Energy Research Institute, Golden, CO, 1989 , p. 115.

8. Simmermacher, T., C. O'Gorman, W. Martin and F. Lopez, Modal Test of SERI-Blade Bl, Internal SNL Memo, Sandia National Laboratories, Albuquerque, July 22, 1999.
9. Buhl, M.L., Jr., and N.L. Weaver, GPP Version 6 User's Guide, A General-Purpose Postprocessor for Wind-Turbine Data Analysis, NREL/TP-500-25815, National Renewable Energy Laboratory, National Wind Technology Center, Boulder, July, 1999.

10. Buhl, M. L., Jr., CRUNCH, vl.8, released by National Renewable Energy Laboratory, National Wind Technology Center, Boulder, October 1, 1999.

12. Kelley, N.D., and H.E. McKenna, "The Evaluation of a Turbulent Loads Characterization System," 1996 ASME Wind Energy Symposium, 1996, p. 69.

12. Kelley, N.D., R.M. Osgood, J.T. Bialasiewicz and A. Jakubowski, "Using Time-Frequency and Wavelet Analysis to Assess Turbulence/Rotor Interactions," 2000 ASME Wind Energy Symposium, 2000, p. 130. 